\title{
EVALUASI PENERAPAN TEKNOLOGI INFORMASI MENGGUNAKAN FRAMEWORK ITIL VERSI 3)
}

\author{
Yulina $1^{1}$, Arif Gunarto $2^{2}$ \\ yulinam.yusuf@yahoo.do.id ${ }^{1}$, 4rifgunarto@gmaik.com² \\ Universitas Muhammadiyah Kotabumi ${ }^{1}$ \\ SMKN 1 Kalianda $^{2}$
}

\begin{abstract}
Higher education institutions is right now required to have a Website as an information services for the entire of academic community and also to the public STIE Muhammadiyah Kalianda feels that the use of Website is unsatisfactory so that the implementation still needs improvement. Appropriate and easy methods user in carrying out the measurement of Website perormance absolutely are needed, the process of evaluating the performance of information technology implementation that used is the Framework Information Technology Infrastructure Library which is expected to provide a comprehensive solutions related to organizational and management conditions. From the results of the research, it can be concluded, that the management and services that carried out by STIE Kalianda have been in the level of the defined process
\end{abstract}

Keywords: Internet, Website, ITIL Framework

Abstrak: Lembaga pendidikan tinggi saat ini dituntut memiliki Website sebagai layanan informasi bagi seluruh sivitas akademika dan juga untuk publik. STIE Muhammadiyah Kalianda merasa bahwa penggunaan Website tidak memuaskan sehingga implementasinya masih perlu ditingkatkan. Metode pengguna yang tepat dan mudah dalam melakukan pengukuran kinerja Website mutlak diperlukan, proses evaluasi kinerja implementasi teknologi informasi yang digunakan adalah Kerangka Kerja Infrastruktur Perpustakaan Teknologi Informasi yang diharapkan dapat memberikan solusi komprehensif terkait kondisi organisasi dan manajemen. Dari hasil penelitian, dapat disimpulkan, bahwa manajemen dan layanan yang dilakukan oleh STIE Kalianda telah berada di tingkat proses yang ditentukan

Kata kunci: Internet, Website, Kerangka kerja ITIL

\section{PENDAHULUAN}

Hadirnya teknologi informasi yang berbasiskan internet merupakan wujud nyata dari perkembangan teknologi informasi, dengan banyaknya website di pada instansi pemerintah maupun swasta telah memberikan perubahan yang besar terhadap layanan public. Begitu juga didunia pendidikan tinggi semua pendidikan tinggi diwajibkan untuk memiliki website sebagai layanan informasi kepada dosen mahasiswa, seluruh civitas akademika dan juga kepada publik.

Evaluasi kepada website yang dimiliki penting dilaksanakan untuk mengetahui tingkat kepuasan dan dan agar dapat masukan yang bermanfaat STIE Muhammadiyah Kalianda. Metode evaluasi digunakan untuk mengambil penilaian terhadap fakta yang ada agar didapatkan 
jalan keluar yang baik dan akhirnya didapat

memberika rekomendasi

Framework Information Technologi

Infrastructure Library Versi 3digunakan untuk mengevaluasi teknologi informasi (TI) pada STIE Muhammadiyah Kalianda. Dengan adanya evaliasi (TI) pada STIE Muhammadiyah Kalianda, diharapkan dapat memberikan rekomendasi dengan dasar identifikasi masalah untukkemudian dihasilkantingkat kematangan penerapan TIi Pada STIE Muhammadiyah Kalianda .

\section{METODE}

Metodelogi yang digunakan untuk menentukan keluaran dari setiap masukan yang ada yaitu dengan cara :

1. Mempersiapkan data kualitatif dan data kuantitatif mengenai factor - factor dominan yang menyebabkan keberhasilan implementasi teknologi informasi seperti pada ITIL

2. Sumber data primer didapat dari hail pengamatan dokumen, Kuesioner atau angket Observasi, Wawancara dengan pimpinan, staf, maupun karyawan karyawati STIE Muhammadiyah Kalianda.

\section{A. Tahapan Metodelogi Penelitian}

Tahapan yangdilakukan pada penelitian ini adalah ebagai berikut

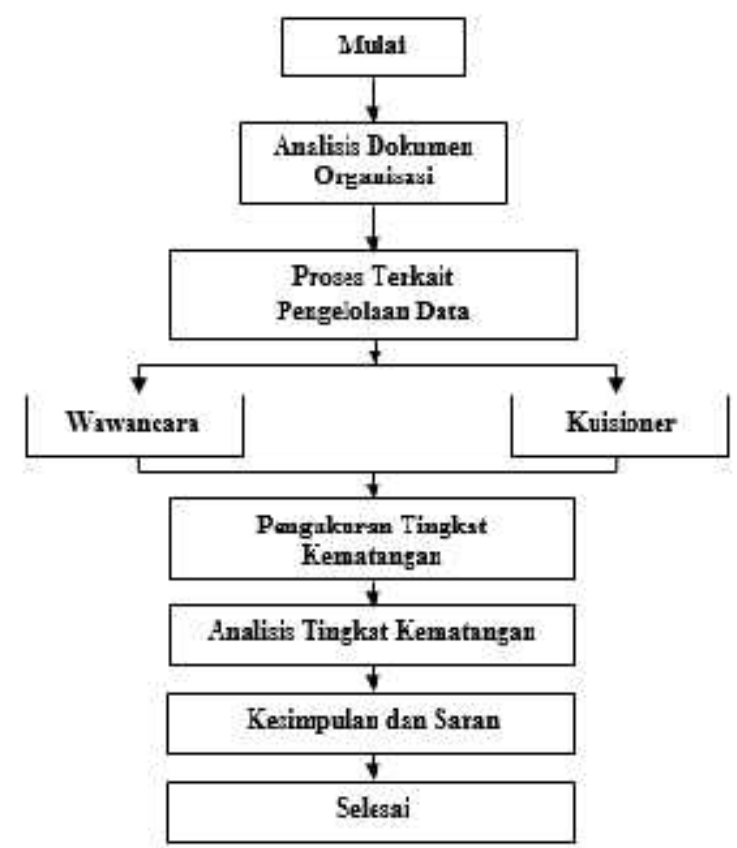

B. Lingkup Audit (SI)

Lingkup Audit item informai diawali dengan melakukan wawancara seperti pada tabel berikut :

\begin{tabular}{|c|c|c|}
\hline $\begin{array}{c}\text { Proses } \\
\text { Pengendalian }\end{array}$ & \multicolumn{2}{|c|}{$\begin{array}{l}\text { Evaluasi faktor resiko, dan } \\
\text { manajemen sitem informasi }\end{array}$} \\
\hline \multirow{3}{*}{$\begin{array}{c}\text { Service } \\
\text { Operation }\end{array}$} & $\begin{array}{l}\text { Event } \\
\text { Management }\end{array}$ & $\begin{array}{l}\text { Melakukan } \\
\text { pengamatan } \\
\text { kepada semua } \\
\text { infrastruktur TI } \\
\text { dalam rangka } \\
\text { untuk untuk } \\
\text { melacak } \\
\text { keadaan yang } \\
\text { ebenarnya. }\end{array}$ \\
\hline & $\begin{array}{l}\text { Incident } \\
\text { Management }\end{array}$ & $\begin{array}{l}\text { proses yang } \\
\text { berfokus pada } \\
\text { pemulihan } \\
\text { kegagalan } \\
\text { layanan } \\
\text { secepatmungkin } \\
\text { bagi pelanggan, } \\
\text { sehingga ini } \\
\text { memiliki } \\
\text { dampak } \\
\text { minimal pada } \\
\text { bisnis }\end{array}$ \\
\hline & $\begin{array}{l}\text { Monitoring } \\
\text { and Control }\end{array}$ & $\begin{array}{l}\text { Berdasarkan } \\
\text { siklus terus- } \\
\text { menerus } \\
\text { pemantauan, }\end{array}$ \\
\hline
\end{tabular}




\begin{tabular}{|l|l|}
\hline & pelaporan dan \\
& Tindakan \\
& usaha. Siklus \\
& ini sangat \\
& penting untuk \\
& menyediakan, \\
& mendukung dan \\
& meningkatkan \\
& jasa. \\
\hline
\end{tabular}

Berdasarkan pembagian domain yang telah ditentukan, maka selanjutnya adalah proses TI yang mendukung tujuan TI tersebut. Tingkat maturity terdiri dari enam level (0 sampai 5.

Data diperoleh dari Kuisioner, yaitu dengan cara membagikan kuisioner kepada dosen dan mahasiswa. dengan rincian

Rincian Responden

\begin{tabular}{|c|c|c|c|}
\hline No & \multicolumn{2}{|r|}{ Kategori Responden } & $\begin{array}{l}\text { Jumlah } \\
\text { Respon }\end{array}$ \\
\hline 1 & $\begin{array}{l}\text { Manaj } \\
\text { emen }\end{array}$ & $\begin{array}{ll}\text { 1. } & \text { Ketua } \\
\text { 2. Waket I } \\
\text { 3. Waket II } \\
\text { 4. Waket III } \\
\text { 5. Unit Penjaminan } \\
\text { Mutu Internal } \\
\text { 6. Ka. Prodi dan } \\
\text { Sekretaris Prodi } \\
\text { 7. Bagian Umum } \\
\text { 8. Bagian Keuangan } \\
\text { 9. Bagian } \\
\text { Kerumahtanggaan } \\
\text { 10. IMM, BEM dan } \\
\text { UKM } \\
\text { 11. PPPI } \\
\text { 12. IKA Alumni } \\
\text { 13. BAAK } \\
\text { 14. Pelaksana Teknis } \\
\text { Perpustakaan } \\
\text { 15. Pelaksanan Teknis } \\
\text { Lab. Komputer } \\
\text { 16. PPPM }\end{array}$ & $\begin{array}{l}1 \\
1 \\
1 \\
1 \\
1 \\
2 \\
1 \\
1 \\
1 \\
3 \\
1 \\
1 \\
1 \\
1 \\
1 \\
1\end{array}$ \\
\hline 2 & User & $\begin{array}{ll}\text { 1. Dosen Manajemen } \\
\text { 2. Mahasiswa } \\
\text { Manajemen }\end{array}$ & $\begin{array}{l}13 \\
57\end{array}$ \\
\hline
\end{tabular}

\section{Teknik Pengolahan Data}

Pengolahan data ini bertujuan untuk menentukan posisi maturity model berdasarkan pendekatan ITIL yang telah dicapai perusahaan pada saat ini. Dalam penelitian ini, digunakan penilaian yang dikemukakan oleh ITGI (2007) adalah sebagai berikut:

\begin{tabular}{|c|c|}
\hline $0-0.5$ & $\begin{array}{l}0 \text { : Non Existent (Tidak } \\
\text { Ada) }\end{array}$ \\
\hline $0.51-1.5$ & 1: Initial / Ad Hoc (Inisial) \\
\hline $1.5-2.5$ & $\begin{array}{l}\text { 2: Repeatable But Intuitive } \\
\text { (Pengulangan Proses } \\
\text { berdasarkan Intuisi) }\end{array}$ \\
\hline $2.51-3.5$ & $\begin{array}{l}\text { 3: Defined Process (Proses } \\
\text { telah didefinisikan) }\end{array}$ \\
\hline $3.51-4.5$ & $\begin{array}{l}4 \text { Managed and } \\
\text { Measurable (Dikelola dan } \\
\text { Terukur) }\end{array}$ \\
\hline $4.51-5$ & $\begin{array}{ll}5 & \text { Optimised } \\
\text { (Optimalisasi) } & \\
\end{array}$ \\
\hline
\end{tabular}

\section{Pelaporan (Reporting)}

Setelah Kuesioner dibagikan selanjtnya data yang didapat kemudian diproses untuk dilakukan perhitungan tingkat maturity dengan tahapan

a. Hasil audit anatara keadaan sekarang dengan harapan

b. Hail analisis tingkat kesenjangan.

c. Mengeluarkan rekomendasi untuk mengatasi tingkat kesenjangan

d. Tindakan yang diambil untuk mendapatkan nilai maksimal.

\section{E. Tindak Lanjut (Follow Up)}

Setelah rekomendasi diserahkan kepada pihak STIE Muhammadiyah Kalianda, maka untuk selanjutnya 
wewenang perbaikan menjadi tanggung jawab pihak STIE Muhammadiyah Kalianda apakah akan diterapkan atau hanya menjadi acuan untuk perbaikan dimasa yang akan datang.

\section{HASIL DAN PEMBAHASAN}

\section{A. Hasil Evaluasi Maturity Level Saat}

\section{Ini (Performance)}

Berdaarkan pengamatan yang dilakukan pada webite STIE Muhammadiyah Kalianda adalah sebagai berikut

.Tabel tingkat kematangan penerapan TI pada level manajemen

\begin{tabular}{|c|l|c|c|}
\hline Domain & \multicolumn{1}{|c|}{ Proses } & $\begin{array}{l}\text { Current } \\
\text { Maturity }\end{array}$ & $\begin{array}{c}\text { Expected } \\
\text { Maturity }\end{array}$ \\
\hline EM.1 & $\begin{array}{l}\text { Events that } \\
\text { indicats a } \\
\text { normal } \\
\text { operation }\end{array}$ & 3,37 & 3,99 \\
\hline & $\begin{array}{l}\text { Events that } \\
\text { indicate an } \\
\text { abnormal } \\
\text { operation }\end{array}$ & 3,38 & 4,14 \\
EM.3 & $\begin{array}{l}\text { Events that } \\
\text { signal an } \\
\text { unusual } \\
\text { but not } \\
\text { exceptional } \\
\text { operation }\end{array}$ & 3,05 & 4,05 \\
\hline IM.1 & Timescales & 3,4 & 4 \\
\hline IM.2 & $\begin{array}{l}\text { Incident } \\
\text { Models }\end{array}$ & 3,45 & 4,07 \\
\hline IM.3 & Impact & 3,52 & 4,1 \\
\hline IM.4 & Urgency & 3,67 & 4,19 \\
\hline IM.5 & Priority & 3,43 & 4,02 \\
\hline IM.6 & $\begin{array}{l}\text { Major } \\
\text { incidents }\end{array}$ & 3,29 & 4,05 \\
\hline MC.1 & Monitoring & 3,31 & 4,17 \\
\hline MC.2 & Reporting & 3,4 & 4,06 \\
\hline MC.3 & Control & 3,27 & 4,22 \\
\hline
\end{tabular}

Tabel tingkat kematangan penerapan TI pada level manajemen pengguna.

\begin{tabular}{|c|c|c|c|}
\hline Domain & Proses & $\begin{array}{l}\text { Current } \\
\text { Maturity }\end{array}$ & $\begin{array}{l}\text { Expected } \\
\text { Maturity }\end{array}$ \\
\hline EM.1 & $\begin{array}{l}\text { Events that } \\
\text { indicase a } \\
\text { normal } \\
\text { overation }\end{array}$ & 3,3 & 4,11 \\
\hline EM.2 & $\begin{array}{l}\text { Events that } \\
\text { indicate an } \\
\text { abnormal } \\
\text { opsration }\end{array}$ & 2,97 & 4,03 \\
\hline EM. 3 & $\begin{array}{l}\text { Events that } \\
\text { signai an } \\
\text { whusual } \\
\text { but not } \\
\text { exceptional } \\
\text { operation }\end{array}$ & 3,25 & 4,07 \\
\hline IM.1 & Timescales & 3,16 & 4,05 \\
\hline IM.2 & $\begin{array}{l}\text { Incident } \\
\text { Modeis }\end{array}$ & 3,12 & 4,03 \\
\hline IM.3 & Impact & 3,24 & 4,06 \\
\hline IM.4 & Urgenty & 3,29 & 4,14 \\
\hline IM.5 & Priority & 3.24 & 4.01 \\
\hline IM. 6 & $\begin{array}{l}\text { Mqjor } \\
\text { incidents }\end{array}$ & 3,54 & 4,04 \\
\hline MC.1 & Monitoring & 3.21 & 4,08 \\
\hline $\mathrm{MC} 2$ & Reporting & 3,14 & 4,12 \\
\hline $\mathrm{MC} 3$ & Control & 3.26 & 4.09 \\
\hline
\end{tabular}

dari hasil kuesioner yang dibagikan kepada 89 orang kaka didapat tingkat kematangan eperti table manajemen dan kematangan uer diatas.

Tingkat kematangan tata kelola TI saat ini dapat digambarkan pada grafik dibawah init :

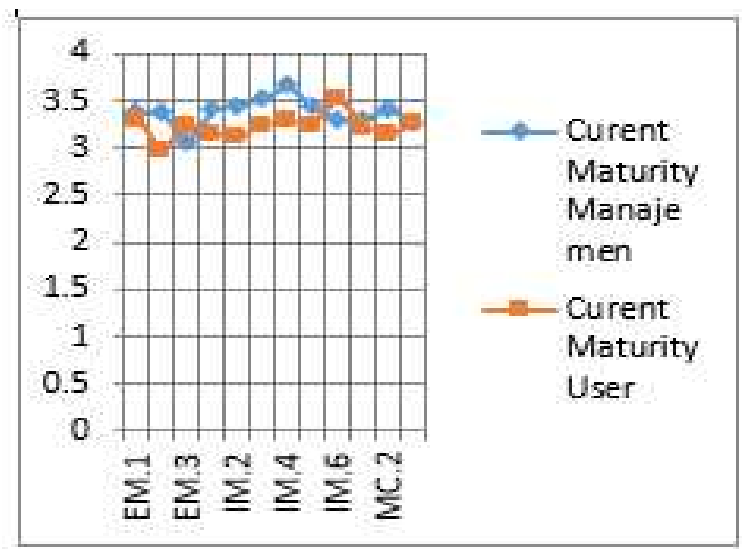

Grafik Performance Manajemen dan User 
Secara umum maturity level penerapan tata kelola TI didapat tingkat kematangan (maturity level) penerapan tata kelola TI pada situs website STIE Muhammadiyah Kalianda didapat dari penjumlahan rata rata setiap katagori

Nilai Maturity dari penerapan tata kelola TI pada STIE Muhammadiyah Kalianda menurut responden user dan manajemen saat ini adalah berada pada level 3 seperti pada tabel dibawah ini:

\begin{tabular}{|l|l|c|}
\hline \multicolumn{1}{|c|}{ Domain } & \multicolumn{1}{|c|}{ Proses } & $\begin{array}{c}\text { Current } \\
\text { Maturity }\end{array}$ \\
\hline $\begin{array}{l}\text { Senvice } \\
\text { Operation }\end{array}$ & Manaiemen & 3,38 \\
\hline $\begin{array}{l}\text { Senvice } \\
\text { Operation }\end{array}$ & User & 3,22 \\
\hline $\begin{array}{l}\text { Nilad Maturiy menurat } \\
\text { Manaiemen dan User }\end{array}$ & 3,30 \\
\hline
\end{tabular}

\section{B. Hasil Evaluasi Maturity Level}

Penerapan tat kelola TI saat ini berdasarkan perhitungan tingkat kematangan pada STIE Muhammadiyah Kalianda seprti pada tabel dibawah ini

Hasil Kuesioner responden kategori manajemen. Untuk penerapan tata kelola TI

\begin{tabular}{|c|l|c|}
\hline Domain & \multicolumn{1}{|c|}{ Proses } & $\begin{array}{c}\text { Expected } \\
\text { Maturity }\end{array}$ \\
\hline EM.1 & $\begin{array}{l}\text { Events that } \\
\text { indicate a normal } \\
\text { operation }\end{array}$ & 3,99 \\
\hline EM.2 that & $\begin{array}{l}\text { Events } \\
\text { indicate an } \\
\text { abnormal } \\
\text { operation }\end{array}$ & 4,14 \\
EM.3 & $\begin{array}{l}\text { Events that signal } \\
\text { an wnusual but } \\
\text { not exceptional } \\
\text { operation }\end{array}$ & 4,05 \\
\hline IM.1 & Timescales & 4 \\
\hline IM.2 & Incident Models & 4,07 \\
\hline IM.3 & Impact & 4,1 \\
\hline IM.4 & Urgency & 4,19 \\
\hline IM.5 & Priority & 4,02 \\
\hline IM.6 & Major mcidents & 4,05 \\
\hline MC.1 & Monitoring & 4,17 \\
\hline MC.2 & Reporting & 4,06 \\
\hline MC.3 & Control & 4,22 \\
\hline & & \\
\hline
\end{tabular}

Hasil Kuesioner responden kategori User. Untuk penerapan tata kelola TI.

\begin{tabular}{|c|lr|c|}
\hline Domain & \multicolumn{2}{|c|}{ Proses } & $\begin{array}{c}\text { Expected } \\
\text { Maturity }\end{array}$ \\
\hline EM.1 & $\begin{array}{l}\text { Events that } \\
\text { indicate a } \\
\text { normal } \\
\text { operation }\end{array}$ & 4,11 \\
\hline EM.2 & $\begin{array}{l}\text { Events that } \\
\text { indicate an }\end{array}$ & 4,03 \\
\hline
\end{tabular}

\begin{tabular}{|c|l|c|}
\hline EM.3 & $\begin{array}{l}\text { Events that } \\
\text { signal an } \\
\text { unusual but not } \\
\text { exceptional } \\
\text { operation }\end{array}$ & 4,07 \\
\hline M.1 & Timescales & 4,05 \\
\hline IM.2 & $\begin{array}{l}\text { Incident } \\
\text { Models }\end{array}$ & 4,03 \\
\hline IM.3 & Impact & 4,06 \\
\hline IM.4 & Urgency & 4,14 \\
\hline IM.5 & Priority & 4,01 \\
\hline M.6 & $\begin{array}{l}\text { Major } \\
\text { incidents }\end{array}$ & 4,04 \\
\hline MC.1 & Monitoring & 4,08 \\
\hline MC.2 & Reporting & 4,12 \\
\hline MC.3 & Control & 4,09 \\
\hline & \multicolumn{2}{|l}{} \\
\hline
\end{tabular}


Hasil Kuesioner responden kategori User dan manajemen. Untuk penerapan tata kelola TI saat ini nilai maturity adalah.

\begin{tabular}{|l|l|c|}
\hline \multicolumn{1}{|c|}{ Domain } & \multicolumn{1}{|c|}{ Proses } & $\begin{array}{c}\text { Expected } \\
\text { Maturity }\end{array}$ \\
\hline $\begin{array}{l}\text { Service } \\
\text { Operation }\end{array}$ & Manajemen & 4,08 \\
\hline $\begin{array}{l}\text { Service } \\
\text { Operation }\end{array}$ & User & 4,06 \\
\hline $\begin{array}{l}\text { Nilai Maturty menurut } \\
\text { Manaiemen dan User }\end{array}$ & 4,07 \\
\hline
\end{tabular}

\section{a. Analisa Kesenjangan Manajemen}

proses penerapan tata kelola TI yang berjalan saat ini adalah pada posisi dibawah expected maturity level. Berikut ini kesenjangan tingkat kematangan penerapan tata kelola TI pada STIE Muhammadiyah Kalianda yang digambarkan dalam tabel 4.7 berikut:

\begin{tabular}{|c|c|c|c|}
\hline Domain & Proses & $\begin{array}{l}\text { Curr } \\
\text { ent } \\
\text { Matu } \\
\text { rity }\end{array}$ & $\begin{array}{l}\text { Expected } \\
\text { Maturity }\end{array}$ \\
\hline SO.1 & $\begin{array}{l}\text { Event } \\
\text { Managem } \\
\text { ent }\end{array}$ & 3,26 & 4,06 \\
\hline SO.2 & $\begin{array}{l}\text { Incident } \\
\text { Managem } \\
\text { ent }\end{array}$ & 3,46 & 4,07 \\
\hline SO. 3 & $\begin{array}{l}\text { Monitorin } \\
g \quad \text { and } \\
\text { Control }\end{array}$ & 3,32 & 4,15 \\
\hline
\end{tabular}

kesenjangan penerapan tata kelola TI.

current maturity level yang berada pada posisi terendah yaitu ada di domain Service Operation pada proses SO.1 yaitu berada pada level 3.26, adapun current maturity level yang berada pada tingkat tertinggi ada pada domain Service Operation pada proses
SO.2 yaitu incident management pada level 3.46 .

Keenjangan tingkat kematangan dari hail kuesioner responden manajemen terlihat pada grafik berikut ini :

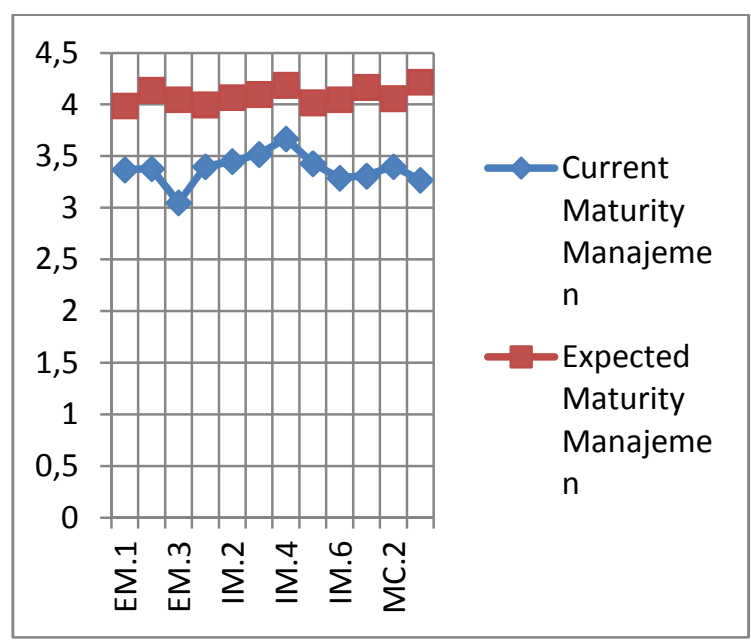

Analisa Kesenjangan tingkat Manajemen

Hasil perhitungan current maturity level untuk proses penerapan tata kelola teknologi informasi saat ini adalah.

\begin{tabular}{|c|l|c|c|}
\hline Domain & \multicolumn{1}{|c|}{ Proses } & $\begin{array}{c}\text { Current } \\
\text { Maturity }\end{array}$ & $\begin{array}{c}\text { Expected } \\
\text { Maturity }\end{array}$ \\
\hline SO.1 & $\begin{array}{l}\text { Event } \\
\text { Management }\end{array}$ & 3,17 & 4,07 \\
\hline SO.2 & $\begin{array}{l}\text { Incident } \\
\text { Management }\end{array}$ & 3,26 & 4,05 \\
\hline SO.3 & $\begin{array}{l}\text { Monitoring } \\
\text { and Control }\end{array}$ & 3,20 & 4,09 \\
\hline
\end{tabular}

Kesenjangan antara tingkat kematangan saat ini dengan tingkat kematangan yang diharapkan terlihat pada grafik berikut : 


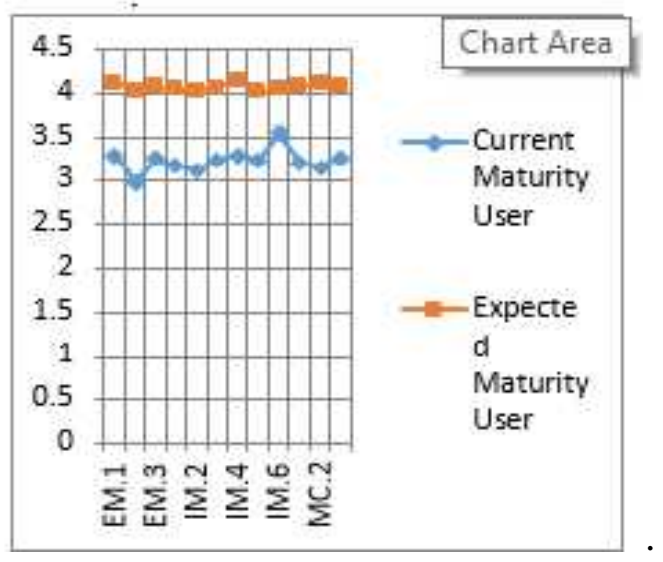

Grafik Analisa Kesenjangan tingkat User

\section{B. Analisa keenjangan proses-proses TI}

Hasil perhitungan gap tingkat kematangan pada responden kategori manajemen dan user pada proses penerapan teknologi informasi pada STIE Muhammadiyah Kalianda digambarkan dalam grafik line berikut :

Gap tingkat kematangan (maturity level) proses penerapan teknologi informasi pada STIE Muhammadiyah Kalianda.

\begin{tabular}{|l|c|c|c|c|}
\hline & $\begin{array}{c}\text { Cure } \\
\text { nt } \\
\text { Matu } \\
\text { rity } \\
\text { Mana } \\
\text { jemen }\end{array}$ & $\begin{array}{c}\text { Curent } \\
\text { Maturit } \\
\text { y User }\end{array}$ & $\begin{array}{c}\text { Expecte } \\
\text { d } \\
\text { Maturit } \\
\text { Manaje } \\
\text { men }\end{array}$ & $\begin{array}{c}\text { Expe } \\
\text { cted } \\
\text { Matu } \\
\text { rity } \\
\text { User }\end{array}$ \\
\hline EM.1 & 3,37 & 3,3 & 3,99 & 4,11 \\
\hline EM.2 & 3,38 & 2,97 & 4,14 & 4,03 \\
\hline EM.3 & 3,05 & 3,25 & 4,05 & 4,07 \\
\hline IM.1 & 3,4 & 3,16 & 4 & 4,05 \\
\hline IM.2 & 3,45 & 3,12 & 4,07 & 4,03 \\
\hline IM.3 & 3,52 & 3,24 & 4,1 & 4,06 \\
\hline IM.4 & 3,67 & 3,29 & 4,19 & 4,14 \\
\hline IM.5 & 3,43 & 3,24 & 4,02 & 4,01 \\
\hline IM.6 & 3,29 & 3,54 & 4,05 & 4,04 \\
\hline MC.1 & 3,31 & 3,21 & 4,17 & 4,08 \\
\hline MC.2 & 3,4 & 3,14 & 4,06 & 4,12 \\
\hline MC.3 & 3,27 & 3,26 & 4,22 & 4,09 \\
\hline
\end{tabular}

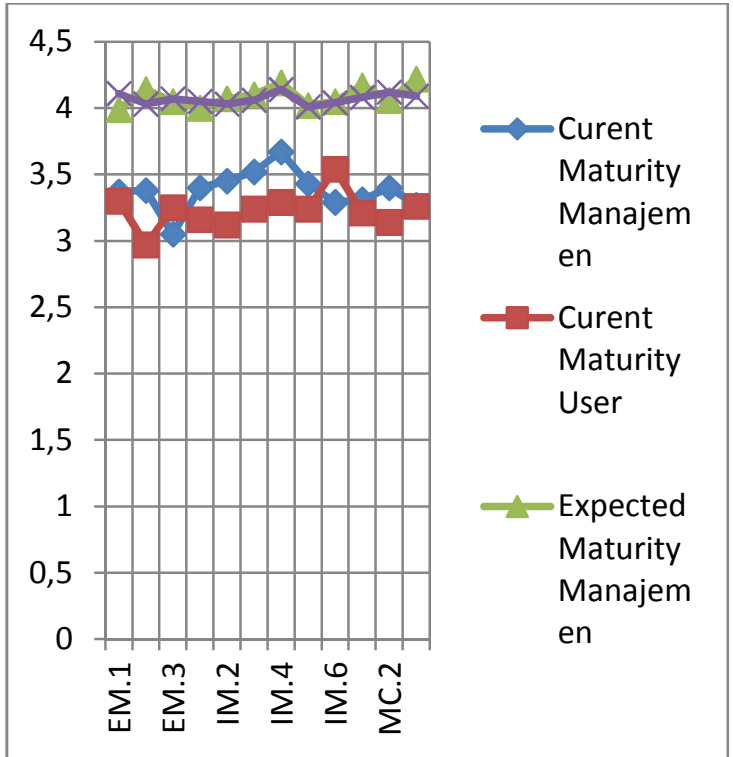

Grafik keenjangan tingkat kematangan proses penerapan TI pada STIE

Muhammadiyah Kalianda.

\section{E. Strategi Peningkatan Layanan Tata}

\section{Kelola TISTIE Muhammadiyah}

\section{Kalianda}

Berdasarkan hasil maturity level, diketahui bahwa maturity level penerapan tata kelola TI secara keseluruhnya berada pada level 3, adapun maturity level yang diharapkan adalah level 4. Untuk mencapai level yang diharapkan perlu dilakukan rencana perbaikan yang menyeluruh pada peroe TI. Kebijakan yang haru diambil manajemen STIE Muhammadiyah Kalianda menurut Control Objective pada ITIL Versi 3 adalah 



\begin{tabular}{|c|c|c|c|c|}
\hline No & Sub Domain & $\begin{array}{l}\text { Kondisi yang } \\
\text { diharapkan }\end{array}$ & Masalah & Solusi \\
\hline 1 & $\begin{array}{l}\text { Event } \\
\text { Management }\end{array}$ & $\begin{array}{l}\text { a. Pengawasan dan } \\
\text { pemantaun kinerja } \\
\text { yang maksimal. } \\
\text { b. Layanan website } \\
\text { mengalami } \\
\text { pertumbuhan dan } \\
\text { perencanaan yang } \\
\text { memadai. } \\
\text { c. Ada standar resmi } \\
\text { proses pengendalian, } \\
\text { perawatan, dan } \\
\text { pengawasan } \\
\text { terhadap layanan } \\
\text { website. }\end{array}$ & $\begin{array}{l}\text { a. Pengawasan dan } \\
\text { pemantaun kinerja } \\
\text { belum maksimal. } \\
\text { b. Layanan website } \\
\text { belum mengalami } \\
\text { pertumbuhan dan } \\
\text { perencanaan yang } \\
\text { memadai. } \\
\text { c. Belum ada standar } \\
\text { resmi proses } \\
\text { pengendalian, } \\
\text { perawatan, dan } \\
\text { pengawasan } \\
\text { terhadap layanan } \\
\text { website. }\end{array}$ & $\begin{array}{l}\text { a. Membuat kerangka } \\
\text { kerja untuk } \\
\text { mendefinisikan layanan } \\
\text { TI apa saja yang } \\
\text { dibutuhkan dan } \\
\text { disediakan bagi } \\
\text { pelayanan kepada } \\
\text { seluruh user. } \\
\text { b. Membuat buku panduan } \\
\text { layanan. } \\
\text { c. Melakukan } \\
\text { pengawasan, membuat } \\
\text { laporan rutin terhadap } \\
\text { kinerja layanan dalam } \\
\text { bentuk formal. } \\
\text { d. Membuat rencana } \\
\text { pengembangan layanan. }\end{array}$ \\
\hline 2 & $\begin{array}{l}\text { Incident } \\
\text { Management }\end{array}$ & $\begin{array}{l}\text { a. Adanya prosedur } \\
\text { baku dalam } \\
\text { penyeleseian } \\
\text { masalah. } \\
\text { b. Adanya staf khusus } \\
\text { yang bertugas dalam } \\
\text { penanganan } \\
\text { masalah. }\end{array}$ & $\begin{array}{l}\text { a. Belum adanya } \\
\text { prosedur baku dalam } \\
\text { penyeleseian } \\
\text { masalah. } \\
\text { b. Belum adanya staf } \\
\text { khusus yang } \\
\text { bertugas dalam } \\
\text { penanganan } \\
\text { masalah. }\end{array}$ & $\begin{array}{l}\text { a. Mengidentifikasi } \\
\text { masalah yang ada dan } \\
\text { mengklasifikasi } \\
\text { berdasarkan tingkat } \\
\text { kerumitan masalah yang } \\
\text { dihadapi. } \\
\text { b. } \\
\text { Memeriksa status } \\
\text { masalah, melakukan } \\
\text { analisis terhadap akar } \\
\text { permasalahan dan } \\
\text { menyelesiakan masalah. } \\
\text { c. } \text { Mendokumentasikan } \\
\text { permasalahan yang } \\
\text { dihadapi, } \\
\text { menginventarisir yang } \\
\text { dapat diselesaikan atau } \\
\text { yang belum dapat } \\
\text { diselesaikan. }\end{array}$ \\
\hline 3 & $\begin{array}{l}\text { Monitoring } \\
\text { and Control }\end{array}$ & $\begin{array}{l}\text { a. Pengawasan yang baik } \\
\text { dari manajemen } \\
\text { terhadap kinerja tata } \\
\text { kelola TI. } \\
\text { b. Manajemen } \\
\text { menerapkan prosedur } \\
\text { resmi terhadap proses } \\
\text { monitoring dan ontrol. }\end{array}$ & $\begin{array}{l}\text { a. Masih kurangnya } \\
\text { pengawasan dari } \\
\text { manajemen terhadap } \\
\text { kinerja } \\
\text { b. Belum diperiapkan } \\
\text { proedur remi oleh } \\
\text { manajemen }\end{array}$ & $\begin{array}{l}\text { a. Melakukan pengawasan } \\
\text { terhadap kinerja tata } \\
\text { kelola TI secara rutin } \\
\text { dan berkelanjutan. } \\
\text { b. Membuat laporan dari } \\
\text { setiap hasil } \\
\text { pengawasan. } \\
\text { c. Mengontrol kinerja } \\
\text { penerapan tata kelola } \\
\text { TI, dan melakukan } \\
\text { tindakan terhadap } \\
\text { kondisi yang ada } \\
\text { dengan tujuan untuk } \\
\text { meningkatkan layanan. }\end{array}$ \\
\hline
\end{tabular}

Tabel Matriks tata kelola TI pada STIE Muhammadiyah Kalianda 


\section{F. Rekomendasi}

Apek yang harus ada dalam penerapan tata kelola TI adalah infrastruktur. Pengelolaan infrastruktur sebaiknya, meliputi: proses pengadaan, penyimpanan, instalai perawatan, pengeloaan infrastruktur yang baik adalah sebagai berikut :

1. Memantau setiap peristiwa yang terjadi Pemantauan setiap peristiwa bertujuan untuk mengetahui keadaan yang sesungguhnya terjadi pada penerapan tata kelola TI, mengenai kinerja dan kualitas situs web dari sisi user. Pemantauan dilakukan secara rutin dan memiliki prosedur baku, hasilnya di evaluasi, dan dibuat secara formal.

2. Pengelolaan situs web

Pengelolaan software bertujuan untuk menjaga dari kemungkina terjadinya masalah dan kesalahan, untuk menghindari hal tersebut diperlukan prosedur pengendalian yang jelas, yang dilengkapi dengan instruksi kerja. Pengelolaan situs web yang baik bertujuan untuk memastikan ketersediaan web disetiap saat, upaya yang dilakukan untuk mengengelola situs web diantaranya:

a. Melakukan pengawasan terhadap aksi yang tidak bertanggung jawab oleh pihak lain. b. Memasang sistem keamanan untuk memprotek sistem informasi / situs web.

3. Penanganan masalah

Untuk menangani masalah - masalah yang terjadi perlu dilakukan persiapkan sebagai berikut :

a. staf teknis yang handal dalam hal penanganan masalah

b. Menyediakan layanan pengaduan bagi user

c. Membuat prosedur baku dalam penanganan masalah

4. Melakukan pengawasan dan kontrol Pengawasan dan kontrol merupakan proses pemantauan, pelaporan, dan memulai tindakan. Pengawasan dan kontrol terhadap penerapan tata kelola TI serta menganalisa kondisi yang sedang dipantau. Adapun tindakan yang harus dilakukan dalam melakukan pengwasan dan kontrol antara lain:

a. Penerapan tata kelola TI sudah berjalan sesuai dengan standar yang telah ada.

b. Tindakan atau respon yang akan dilakukan harus didefinisikan, dan disetujui.

\section{SIMPULAN}

Penelitian yang dilakukan pada STIE Muhammadiyah Kalianda memperoleh hasil bahwa peroses event, monitoring dan kontrol manajemen pada domain Service 
Operation yang diberikan oleh situs website

STIE Muhammadiyah Kalianda berada pada tingkat kematangan defined process.

Pedoman pada penerapan tata kelola

TI di STIE Muhammadiyah Kalianda menggunakan kerangka kerja ITIL Versi 3.

Dari hasil kuesioner yang disebarkan terdapat :

1. expected maturity level di level managed and measurable pada level 4.

2. Keenjangan yang terjadi pada tingkat user dan juga manajemen menunjukkan tidak terlalu bear. Sehingga dapat diambil kesimpulan bahwa apa yang diharapkan oleh manajemen sudah terpenuhi dan sistem sudah dijalankan. Rekomendasi yang dapat peneliti ajukan adalah tambahkan domain-domain yang dinilai sehingga hasilnya akan menjadi lebih baik dari saat ini.

\section{DAFTAR PUSTAKA}

Budiyono, Nugroho. Eko, dan Winarno. Wing Wahyu. (2012). Implementasi ITIL® V3 Framework pada Perancangan Aplikasi Service Desk Management Berorientasi User. JNTETI, Vol. 1, No. 2, Agustus 2012

Cahyaningtyas, AR. Anggun., Rahardja, Yani dan Fridz W, Agustinus. (2012). Audit Sistem Informasi dengan ITIL Version 3 Sub Domain Service Desk, Incident Management, dan Problem Management di Bidang Keuangan Dishubkombudpar Kota Salatiga. Universitas Kristen Satya Wacana. Jurnal Teknologi Informasi-Aiti, Vol. 9. No.2, Agustus 2012 : $101-200$

Effendi. M. Junius, dan Sari. Yusi Nurmala. (2016). Evaluasi Penerapan Teknologi Informasi Pada STIE - AMIK Lembah Dempo Pagaralam Menggunakan Framework Information Technology Infrastructure Library (ITIL Versi 3). Seminar Nasional Teknologi Informasi dan Multimedia 2016. STMIK AMIKOM Yogyakarta, 6-7 Februari 2016. ISSN : 2302-3805

Handayani. Aditya dan Imelda. 2014. Audit Teknologi Informasi Pada CV. X. Jurnal Teknologi dan Informasi UNIKOM, Volume 1 No 6, Tue, 22 Apr 2014

Waspada. Indra, Bahtiar. Nurdin, Saputra. Ragil, dan Hafiizh. Muhammad. (2013). Kerangka Pemilihan Perangkat Lunak Service Desk Sebagai Rekomendasi Implementasi It Service Management (ITSM) (Studi Kasus: UP2TI Fakultas Sains dan Matematika Universitas Diponegoro). Himsya-Tech Vol. 9 No.2, Juni 2013 ISSN 1907-2074

Wibowo. Aldi Satriani, Adipta. Dani, dan Selo. (2016). Kombinasi Framework Cobit 5, ITIL Dan ISO/IEC 27002 Untuk Membangun Model Tata Kelola Teknologi Informasi Di Perguruan Tinggi. Seminar Nasional Teknologi Informasi dan Komunikasi 2016 (SENTIKA 2016) ISSN: 2089-9815. Yogyakarta, 18-19 Maret 2016.

Zavier. Ahmad Faiz, Tanuwijaya. Haryanto, dan Hermawan. Budi. (2014). Audit Pengelolaan Layanan Teknologi Informasi Berdasarkan ITIL Pada IT Marketing \& Trading (M\&T) PT. 
Pertamina (Persero) Marketing Operation Region V Surabaya. Jurnal Sistem Informasi, JSIKA Vol 3, No 2 (2014) ISSN 2338-137X. 